\title{
Enhanced Structural, Thermal, and Electrical Properties of Multiwalled Carbon Nanotubes Hybridized with Silver Nanoparticles
}

\author{
Yusliza Yusof, ${ }^{1}$ Mohd Irwan Zaidi, ${ }^{1}$ and Mohd Rafie Johan ${ }^{1,2}$ \\ ${ }^{1}$ Nanomaterials Engineering Research Group, Department of Mechanical Engineering, University of Malaya, \\ Lembah Pantai, 50603 Kuala Lumpur, Malaysia \\ ${ }^{2}$ Nanotechnology and Catalytic Research Center, University of Malaya, Lembah Pantai, 50603 Kuala Lumpur, Malaysia
}

Correspondence should be addressed to Mohd Rafie Johan; mrafiej@um.edu.my

Received 17 March 2016; Revised 7 June 2016; Accepted 18 July 2016

Academic Editor: Erwan Rauwel

Copyright (c) 2016 Yusliza Yusof et al. This is an open access article distributed under the Creative Commons Attribution License, which permits unrestricted use, distribution, and reproduction in any medium, provided the original work is properly cited.

\begin{abstract}
The objective of this study is to evaluate the structural, thermal, and electrical properties of multiwalled carbon nanotubes (MWNT) hybridized with silver nanoparticles (AgNP) obtained via chemical reduction of aqueous silver salt assisted with sodium dodecyl sulphate (SDS) as stabilizing agent. Transmission electron microscopy (TEM) reveals microstructural analysis of the MWNT-Ag hybrids. The Fourier transform infrared (FTIR) spectra prove the interactions between the AgNP and carboxyl groups of the MWNT. Raman spectra reveal that the D- to G-band intensity ratios $I_{\mathrm{D}} / I_{\mathrm{G}}$ and $I_{\mathrm{D}^{\prime}} / I_{\mathrm{G}}$ increase upon the deposition of AgNP onto the surface of the MWNT. Thermogravimetric analysis (TGA) shows that the MWNT-Ag hybrids decompose at a much faster rate and the weight loss decreased considerably due to the presence of AgNP. Nonlinearity of current-voltage $(I-V)$ curves indicates that electrical transport of pristine MWNT is enhanced when AgNP is induced as charge carriers in the MWNT-Ag hybrids. The threshold voltage $V_{\text {th }}$ value for the MWNT doped with a maximum of 70 vol\% of AgNP was substantially reduced by $65 \%$ relative to the pristine MWNT. The MWNT-Ag hybrids have a favourable electrical characteristic with a low threshold voltage that shows enhancement mode for field-effect transistor (FET) applications.
\end{abstract}

\section{Introduction}

Studies on carbon nanotubes (CNT) have grown rapidly since their discovery by Iijima in 1991 [1]. CNT are composed of graphene layers which are rolled up cylindrically and the diameter of these nanomaterials is within the nanometre scale. CNT consist entirely of $\mathrm{sp}^{2}$ carbon-carbon bonds and they possess unique structural, mechanical, electronic, and optical properties [2-4].

Metal nanoparticles (NP) are an emerging class of compounds with unique properties and they are remarkably different compared to their bulk materials. Examples of metal NP include gold $(\mathrm{Au})$, palladium $(\mathrm{Pd})$, platinum $(\mathrm{Pt})$, and silver (Ag) NP [5]. Detailed studies have been carried out in recent years to integrate the properties of CNT and NP due to their potential applications. This integration has created a new class of hybrid materials that exhibit mixing characteristics at the microscopic level with unique properties that are comparable to the nanocomposites. In addition, CNT possess high aspect ratios because of their smaller diameters and longer lengths, and this makes it possible to functionalize CNT as templates for NP assemblies as well as enhance their properties [2].

Among the various metal NP, silver nanoparticles (AgNP) have been proven to have excellent properties which make them desirable for use in biosensors [6], catalysts [7], antimicrobial agents [8], optical limiters [9], metal adsorbents [10], and advanced composites [11]. One of the major applications of CNT is as active elements in field-effect transistors (FETs) $[12,13]$. According to Bonard et al. [12], the threshold voltage $\left(V_{\text {th }}\right)$ of CNT-based field emitters can reach as low as $4.6 \mathrm{~V}$, unlike diamond-based ones which have a threshold voltage $40 \mathrm{~V}$. For this reason, it is indeed appealing to integrate CNT with metal NP in order to produce CNT-based field emitters 
with lower threshold voltages and higher amplification factors [14].

There are various techniques used to synthesize CNTAg hybrids such as dry and wet chemistry methods. Dry methods are accomplished by physical vaporization of solid precursor materials, producing charged AgNP. These charged AgNP are then directly assembled onto the outer CNT surface. Examples of dry methods are vapor deposition [9], thermal decomposition [15], gamma irradiation [16], and electrostatic force directed assembly (ESFDA) [17]. However, wet chemistry methods are commonly used to deposit AgNP onto the CNT surface since they are fast and relatively inexpensive compared to other NP synthesis methods. In addition, wet chemistry methods provide ease of control over the dimension, morphology, and size distribution of AgNP [18]. Wet chemistry methods generally involve chemical reduction of Ag salt precursors in the presence of CNT and the AgNP are then deposited directly onto the functionalized surface [19-21]. Alternatively, the AgNP can be preformed as metal colloids and then grafted onto the CNT surface by covalent bonding through organic fragments [22].

Interactions between the $\mathrm{AgNP}$ and the $\mathrm{CNT}$ surface may occur through strong covalent bonds or weak intermolecular bonds such as $\pi-\pi$ stacking, hydrophobic interactions, hydrogen bonds, or electrostatic attraction [23]. CNT are by nature hydrophobic and they tend to self-aggregate due to strong van der Waals forces. Hence, surface modification of CNT through functionalization is commonly required to promote several active groups (i.e., $-\mathrm{OH},-\mathrm{C}=\mathrm{O},-\mathrm{C}-\mathrm{O}$, and $-\mathrm{COOH}$ ) on the sidewalls of the nanotubes. This, in turn, enhances the binding mechanism between the metal NP and the CNT surface [24]. However, it shall be noted that functionalization of CNT using strong oxidation treatments results in severe structural damage which may affect some properties of the CNT [25]. Despite the technological advancements in materials science over the years, it is still challenging to devise a suitable method to deposit AgNP onto the CNT surface with fewer defective structures. In addition, the weak interaction between the AgNP and the CNT surface as well as agglomeration of the AgNP results in only a few AgNP being deposited onto the CNT surface $[2,11,26]$.

In this work, MWNT-Ag hybrids are synthesized through a simple reduction method, whereby N,N-dimethylformamide (DMF) and sodium dodecyl sulphate (SDS) are used as the reducing agent and surfactant, respectively. Following this, the structural, morphological, thermal, and electrical properties of MWNT-Ag hybrids are examined using various characterization techniques.

\section{Materials and Methods}

2.1. Materials. MWNT (purity $>95 \mathrm{wt} \%$ ) were purchased from Legend Star International Co., Ltd., Taiwan, whereby the outer diameter and length of the MWNT are within a range of $20-30 \mathrm{~nm}$ and $10-30 \mu \mathrm{m}$, respectively. The silver nitrate $\left(\mathrm{AgNO}_{3}, 0.1 \mathrm{~mol} / \mathrm{L}\right)$, sodium dodecyl sulphate (SDS), and $\mathrm{N}, \mathrm{N}$-dimethylformamide (DMF) were purchased from a local supplier, R\&M Chemicals.
2.2. Synthesis of MWNT-Ag Hybrids. Firstly, the MWNT were functionalized using nitric acid $\left(\mathrm{HNO}_{3}, 65 \%\right)$, followed by hydrogen peroxide $\left(\mathrm{H}_{2} \mathrm{O}_{2}, 30 \%\right)$. Following this, $1 \mathrm{~g}$ of MWNT was treated with $100 \mathrm{~mL}$ of $\mathrm{HNO}_{3}$ in an ultrasonic bath for $30 \mathrm{~min}$. The $\mathrm{MWNT}+\mathrm{HNO}_{3}$ mixture was then diluted with deionized water and filtered through the polycarbonate membrane. The filtered product was washed with deionized water several times until the $\mathrm{pH}$ value becomes neutral. The steps were repeated by substituting the solvent with $\mathrm{H}_{2} \mathrm{O}_{2}$. The carboxylic acid-functionalized MWNT (MWNT-COOH) solids obtained were then dried in a laboratory oven set at $60^{\circ} \mathrm{C}$ for $24 \mathrm{~h}$.

The AgNP formed on the MWNT surface by the reduction of $\mathrm{Ag}^{+}$from the silver salt $\left(\mathrm{AgNO}_{3}\right)$ in the presence of MWNT. In this work, $0.5 \mathrm{~g}$ of functionalized MWNT and $0.2 \mathrm{~g}$ of sodium dodecyl sulphate (SDS) were added into $250 \mathrm{~mL}$ of N,N-dimethylformamide (DMF). The mixture was then ultrasonicated for $30 \mathrm{~min}$. The solution was then heated to $80^{\circ} \mathrm{C}$, followed by the addition of $\mathrm{AgNO}_{3}(0.1 \mathrm{~mol} / \mathrm{L})$ at different volumes such that the concentration of $\mathrm{Ag}$ to $\mathrm{C}$ was $10,30,50$, and $70 \mathrm{vol} \%$. The hot solution was stirred continuously for $1 \mathrm{~h}$ and left to cool to room temperature for $24 \mathrm{~h}$. The product was then filtered and washed with ethanol, water, and acetone several times. Finally, the MWNT-Ag powders obtained were dried at $60^{\circ} \mathrm{C}$ for $24 \mathrm{~h}$.

\subsection{Characterization of MWNT-Ag Hybrids. Field-emission} scanning electron microscope (JEOL, JSM 7600-F) was used to examine the surface morphology of the MWNT$\mathrm{Ag}$ hybrids whereas elemental analysis was carried out using energy dispersive X-ray spectrometer (EDX). The size and structure of the samples were analysed using transmission electron microscope (JEOL, JEM 2100-F). The samples were ultrasonically dispersed in deionized water and the nanotube suspension was then dropped once onto a copper grid and dried at room temperature for three days.

The Fourier transform infrared spectrometer (Perkin Elmer, Spectrum $400 \mathrm{WA}$ ) was used to record the FTIR spectra of the MWNT-Ag hybrids within a wavenumber range of $400-4000 \mathrm{~cm}^{-1}$ with a scan rate of $16 \mathrm{~cm}^{-1} / \mathrm{min}$. MicroRaman spectrometer (HORIBA Scientific, JOBIN YVON) was used to characterize the vibrational properties and structural changes of the CNT in the presence of AgNP. The spectrometer is equipped with a CCD detector and a solid state excitation green laser with an excitation wavelength of $532 \mathrm{~nm}$. The acquisition time was set at $30 \mathrm{~s}$ for at least two cycles.

Thermogravimetric analyser (Mettler Toledo, SDTA851e) was used to evaluate the thermal stability of the samples in an air atmosphere. Approximately $10 \mathrm{mg}$ of dry samples was added into an aluminium pan and the test was carried out at a heating rate of $10^{\circ} \mathrm{C} / \mathrm{min}$ within a temperature range of 40-1000 ${ }^{\circ}$ C. Potentiostat/galvanostat instrument (Metrohm Autolab, NOVA) was used to measure the current-voltage $(I-V)$ characteristics of the samples. The parameters were adjusted using the linear sweep voltammetry (LSV) staircase command dialog boxes with a scan rate of $0.05 \mathrm{~V} / \mathrm{s}$ and step 

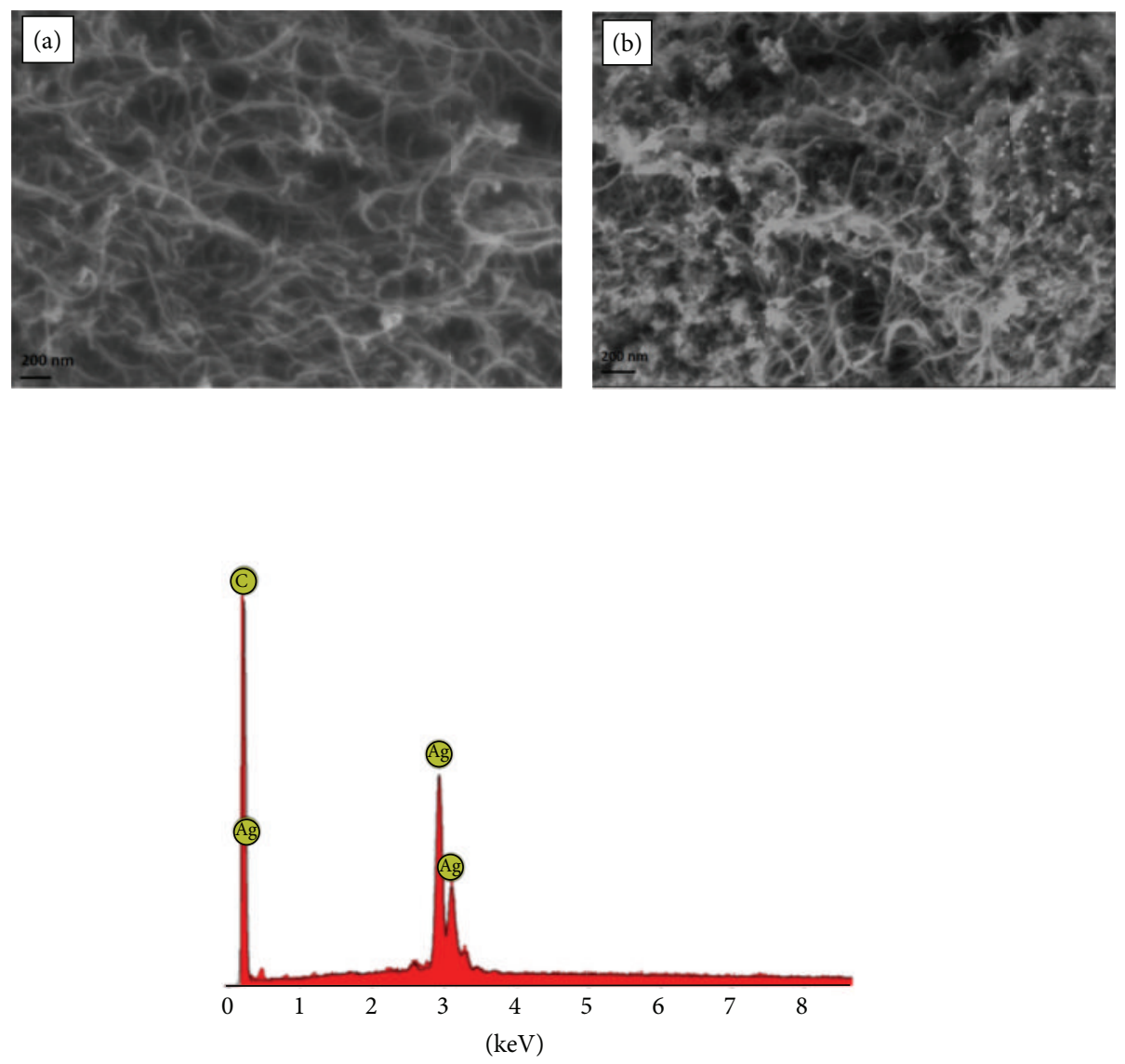

209,866 counts in 373 seconds

(c)

FIGURE 1: FESEM images of (a) pristine MWNT, (b) MWNT-Ag hybrids, and (c) EDX spectrum of the MWNT-Ag hybrids.

potential of $0.20 \mathrm{~V}$. The applied voltage was within a range of $1-10 \mathrm{~V}$.

\section{Results and Discussion}

3.1. Morphological Analysis. Figures 1(a) and 1(b) show FESEM image of pristine MWNT before and after the nanoparticle synthesis, respectively. The morphology of MWNT-Ag hybrids in Figure 1(b) shows bright and spherical images of $\mathrm{Ag}$ nanoparticles anchored onto the MWNT surface. This is accompanied with EDX spectrum that shows an intense signal of $\mathrm{C}$ coupled with Ag signals which confirm the presence of Ag onto the MWNT surface.

Figures 2(a)-2(d) show the TEM images of MWNT-Ag hybrids with 10, 30, 50, and 70 vol\% of AgNP. The MWNT have open-ended structures with an average size of $20-30 \mathrm{~nm}$, whereas the presence of AgNP is denoted by much smaller particles with an average diameter of 5-10 nm. Figure 2(e) shows high-resolution TEM image of AgNP that was almost spherical in shape and is deposited onto the outer surface of MWNT.

It can be observed that MWNT are much bent with increasing AgNP assembled onto the nanotube surface due to the presence of defect in the graphitic network. The more
AgNP produced also have a high tendency to aggregation and growth to the formation of Ag clusters due to its steric effect [27]. This circumstance captivated the MWNT that have been much kinked to accumulate around the NP due to insufficient debundling power of anionic surfactant to disperse individual nanotubes because of its high van der Waal attractions. It seems that there was inadequate amount of SDS for 50 and 70 vol $\%$ agNP to be used as stabilizer and adsorbed onto the MWNT when the concentration of Ag is high enough but the concentration of SDS remained same. In addition, mild oxidation treatment based on sonicating the MWNT in $\mathrm{HNO}_{3}$ followed by $\mathrm{H}_{2} \mathrm{O}_{2}$ might limit the formation of carboxylic groups on the MWNT surface $[25,28]$.

Some of the AgNP are isolated around the nanotubes probably due the homogeneous nucleation of NP which later grow to larger aggregated NP. The addition of SDS is required to support the heterogeneous nucleation for fine NP dispersion nucleated onto the functionalized MWNT surface [23]. The interactions between carboxyl groups and the Ag cations $\left(\mathrm{Ag}^{+}\right)$resulted in self-assembly of AgNP onto the functionalized MWNT. The self-assembly process involved the electrostatic interactions between SDS molecules with $\mathrm{Ag}^{+}$to obtain positively charged Ag-SDS nanoparticles, which assembled with negative charge from carboxylic 


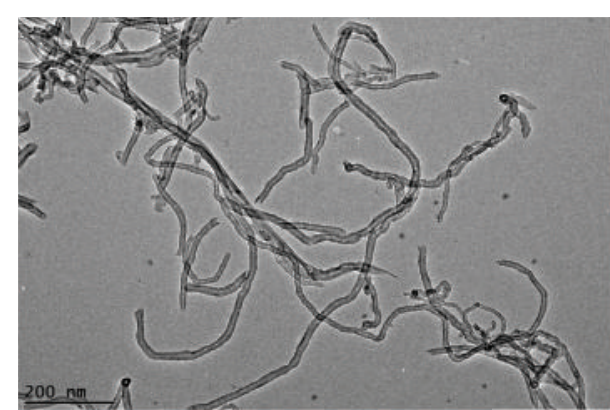

(a)

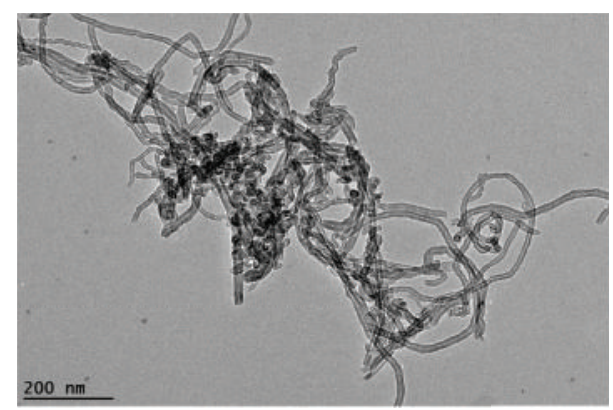

(c)

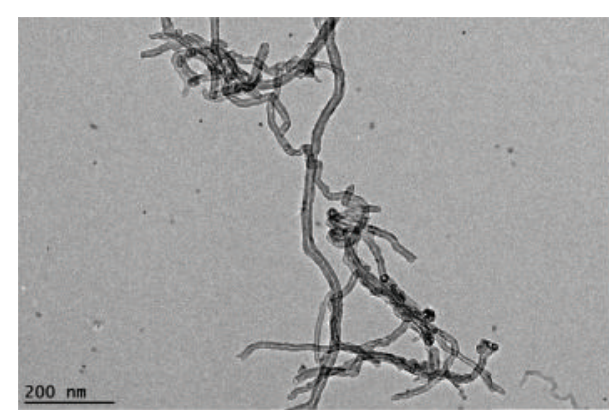

(b)

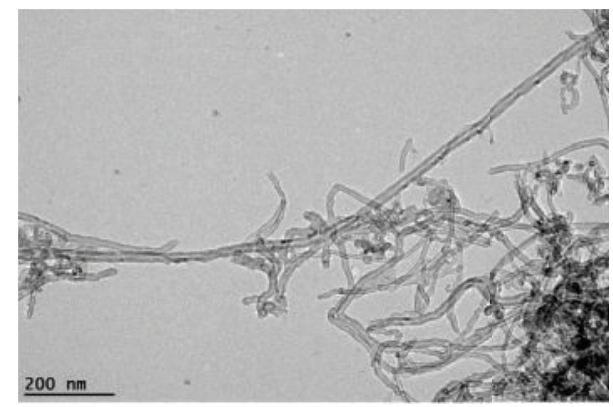

(d)

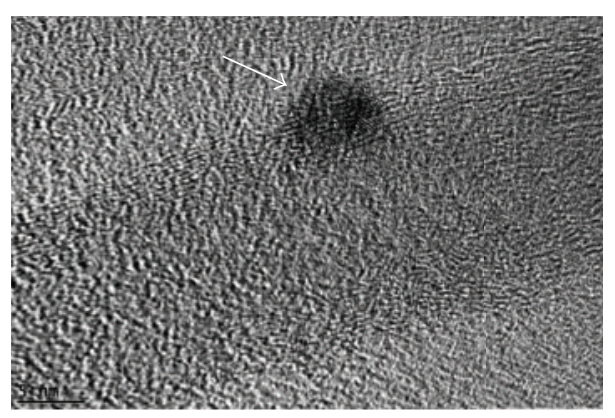

(e)

FIGURE 2: TEM images of MWNT-Ag hybrids with different vol\% of AgNP: (a) 10, (b) 30, (c) 50, and (d) 70 and (e) HRTEM showing AgNP deposited onto the MWNT surface.

groups created on sidewalls of the nanotubes. This can be illustrated as in Figure 3 which shows the mechanism for direct deposition of AgNP onto the surface of the MWNT. However, the adsorption of ionic surfactant much depends on the amount of purification and functionalization of the nanotube surfaces. The AgNP also can be nucleated via precipitation with functionalized CNT without addition of ionic surfactant, but strong chemical oxidation can cause severe damage to the nanotube structure [24]. The drawback of severe CNT damage can limit their great potential as electrical reinforcement. Instead, the adsorption of the SDS molecules also may occur without functionalization of the nanotubes. The decoration of AgNP is attained from supramolecular self-assembly of the SDS molecules onto the surface of the nanotubes. It is promoted through electrostatic interactions between the hydrophobic linear chains of the SDS molecules and the sidewalls of the nanotubes [29].
3.2. FTIR Analysis. Figure 4 shows the FTIR spectra of pristine MWNT and MWNT-Ag hybrids with 10, 30, 50, and $70 \mathrm{vol} \%$ of AgNP. Figure 4(a) shows the presence of characteristic peaks within a wavenumber range of 1100$1380 \mathrm{~cm}^{-1}$ which are attributed to C-C stretching band of pristine MWNT [25]. The appearance of prominent peaks centred at $1720 \mathrm{~cm}^{-1}$ and $1170 \mathrm{~cm}^{-1}$ are attributed to $\mathrm{C}=\mathrm{O}$ and $\mathrm{C}-\mathrm{O}$ bands, respectively, which are arising from the carboxylic functional groups [30-32]. The characteristic peaks at $2380 \mathrm{~cm}^{-1}$ are associated with the $\mathrm{O}-\mathrm{H}$ bending deformation mode from the hydrogen bonds of the carboxylic groups. The presence of these peaks indicates that some oxygenated groups have been introduced to the nanotube walls, which may serve as nucleation sites for the reduction of $\mathrm{Ag}$ ions $\left(\mathrm{Ag}^{+}\right)$. The other characteristic peaks which appear at a wavenumber of $760 \mathrm{~cm}^{-1}$ correspond to $-\mathrm{CH}_{2}$ rocking [33].

It can be seen from the FTIR spectra of the MWNTAg hybrids (Figure 4(b-e)) that the transmittance intensity 

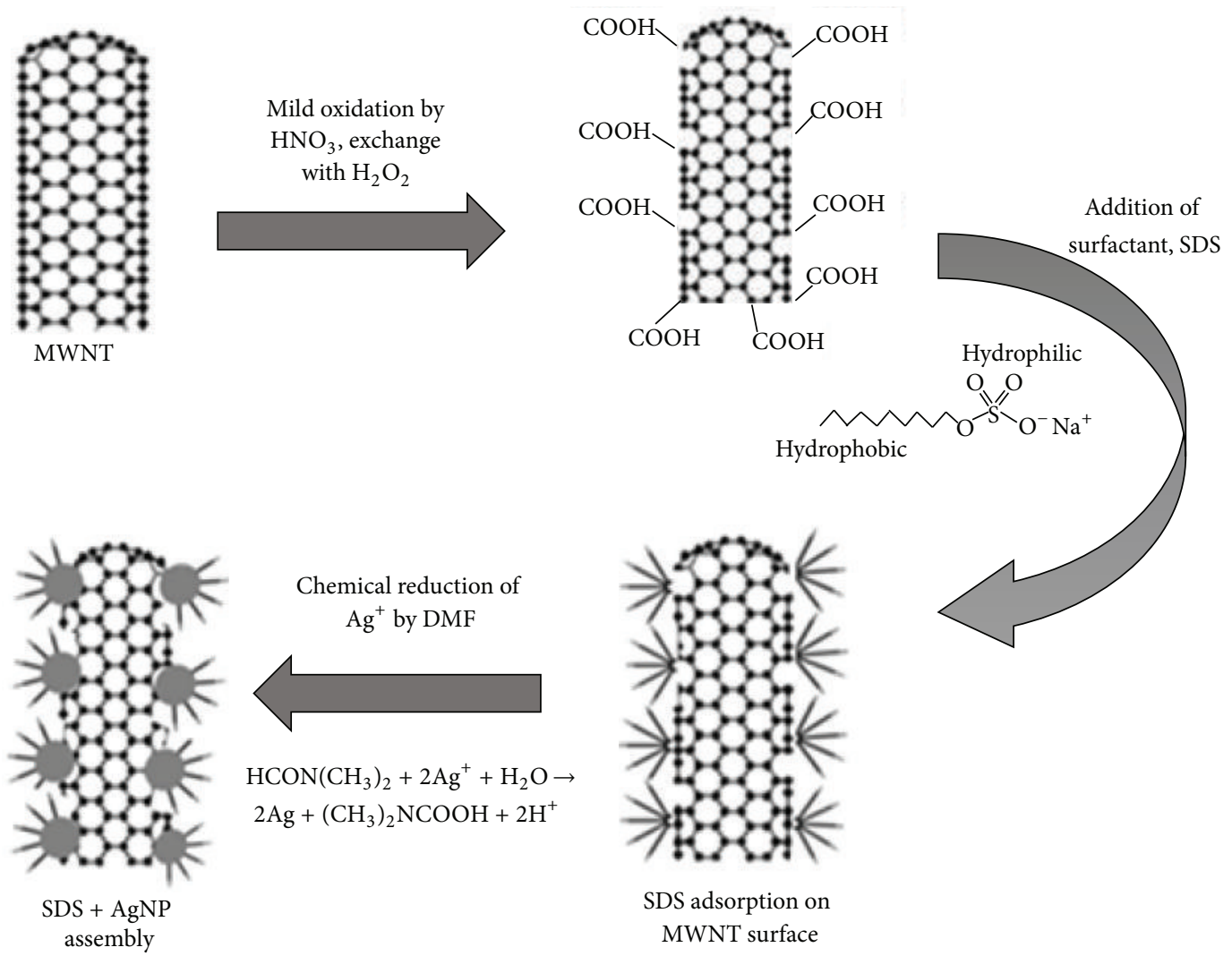

FIGURE 3: A schematic diagram which shows the mechanism for direct deposition of AgNP onto the MWNT surface.

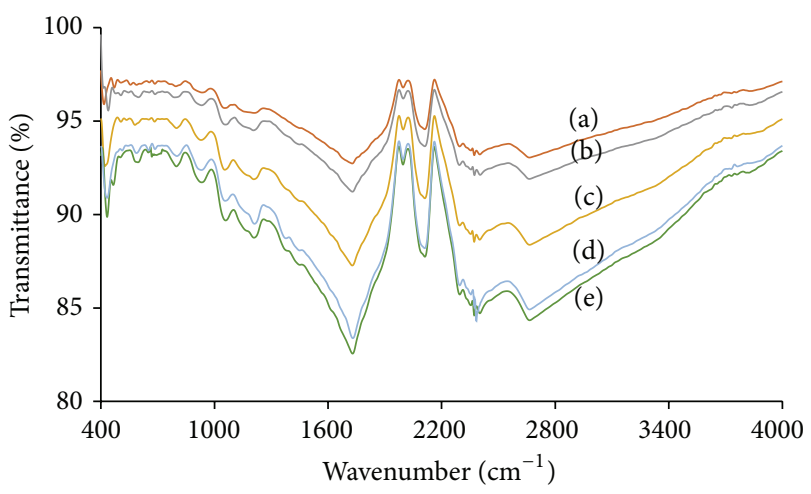

FIGURE 4: FTIR spectra of (a) pristine MWNT and MWNT-Ag hybrids with different vol\% of AgNP (b) 10, (c) 30, (d) 50, and (e) 70 .

decreases for $\mathrm{C}-\mathrm{O}, \mathrm{C}=\mathrm{O}$, and $\mathrm{O}-\mathrm{C}=\mathrm{O}$ upon the addition of AgNP. This suggests that the AgNP are attached to the surface of the MWNT via carboxylic groups and/or they physically stick to the surface via van der Waals forces, weak intermolecular interactions such as $\pi-\pi$ stacking, and/or electrostatic attractions [23]. These results confirm the attachment of AgNP onto the surface of the MWNT. The broad peaks centred at $3350 \mathrm{~cm}^{-1}$ are attributed to the presence of the hydroxyl $(-\mathrm{OH})$ group due to the interactions between the $-\mathrm{OH}$ group and AgNP as well as other functional groups on the surface of the MWNT [24]. Thus, C-O-Ag and
$\mathrm{O}=\mathrm{C}-\mathrm{O}-\mathrm{Ag}$ bonds are formed after removal of $\mathrm{H}_{2} \mathrm{O}$. The existence of small peaks at $1460 \mathrm{~cm}^{-1}$ is due to the interaction of carbon with AgNP. This results in $\mathrm{C}=\mathrm{C}$ stretching even though the intensity of the $\mathrm{C}=\mathrm{C}$ bond of the MWNT is previously weakened by nitric acid treatment [26].

3.3. Raman Analysis. Figure 5(a)(A-E) shows the Raman spectra of pristine MWNT and MWNT-Ag hybrids with different volume fractions of AgNP, and it can be observed that there are two prominent features (D- and G-bands) at 1340 and $1580 \mathrm{~cm}^{-1}$, respectively. The D-band is attributed to the vibrational mode which originates from the disordered structure of graphite, whereas the G-band is attributed to the tangential radial mode of $\mathrm{sp}^{2}$ bonded carbon atoms in graphite [34]. It is apparent that the intensity of the D-band is higher than that of the G-band in pristine MWNT, indicating the existence of a more disordered structure in the nanotubes.

The D- and G-bands of MWNT-Ag hybrids are considerably broader than pristine MWNT due to the assembly of AgNP with different sizes and distribution that is modulating the microenvironment of the MWNT to be more diverse [8]. In addition, the peaks broadening of MWNTAg hybrids suggests that the deposition of AgNP ensures the occurrence of charge-transfer from the silver ions to the MWNT. This interaction is enhanced through hydrophobic interaction with SDS molecules that cause a substantial change in electronic density state of the nanotubes [29]. 


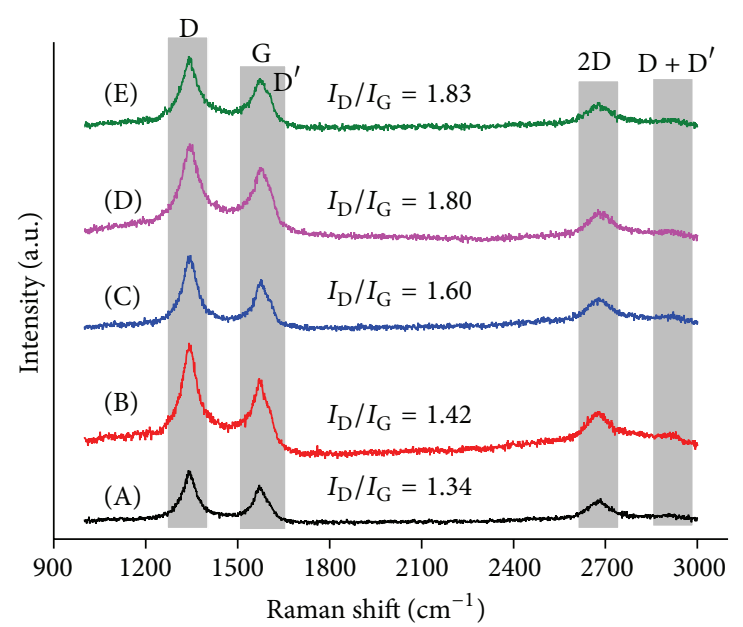

(a)

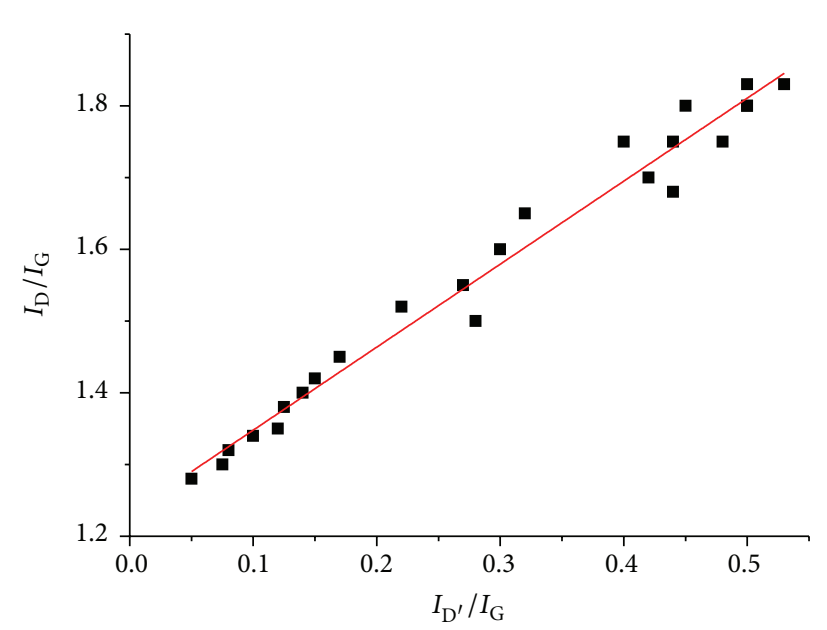

(b)

Figure 5: (a) Raman spectra of (A) pristine MWNT and MWNT-Ag hybrids with different vol\% of AgNP (B) 10, (C) 30, (D) 50, and (E) 70 and (b) plotted graph of $I_{\mathrm{D}} / I_{\mathrm{G}}$ versus $I_{\mathrm{D}^{\prime}} / I_{\mathrm{G}}$.

The D- to G-band intensity ratio $\left(I_{\mathrm{D}} / I_{\mathrm{G}}\right)$ for pristine MWNT is 1.34 , indicating a typical value of nanotubes having a more disordered graphite structure. In fact, the $I_{\mathrm{D}} / I_{\mathrm{G}}$ value of MWNT-Ag hybrids increases with an increase in the volume fraction of the AgNP. This indicates that the deposition of AgNP creates defects such as non-sp ${ }^{2}$ carbon dangling bonds in the MWNT structures [35]. The increase of intensity of $\mathrm{D}$-band is associated with the presence of relatively small intensity of $\mathrm{D}^{\prime}$ peaks that appear as a shoulder on the right side of the $G$ peak due to the increase of disorder graphite structure. Figure 5(b) shows the linear dependence between $I_{\mathrm{D}} / I_{\mathrm{G}}$ and $I_{\mathrm{D}^{\prime}} / I_{\mathrm{G}}$ because the $I_{\mathrm{D}^{\prime}} / I_{\mathrm{G}}$ ratio also increases by adding more AgNP with MWNT. Considering the $I_{\mathrm{G}}$ as constant, the $\mathrm{D}$ and $\mathrm{D}^{\prime}$ intensities are found to proportionally increase with the amount of defects created in $\mathrm{sp}^{2}$ carbon hybridized with AgNP. However the proportionality factor may vary depending on the different type of defects present in the nanotube structures. This is in agreement with work done by Eckmann et al. who extracted in detail the nature of defects in graphene by Raman spectroscopy [36]. The presence of $\mathrm{G}^{\prime}$-band or $2 \mathrm{D}$-band at $2670 \mathrm{~cm}^{-1}$ is due to the two-phonon scattering which is sensitive to the defect density and purity of the MWNT [37]. The intensity of the $G^{\prime}$-band also evolves from metallicity enriched within the nanotubes [38]. The interaction of AgNP with MWNT may induce a slight increase in its metallicity. It suggests that when one $\mathrm{Ag}$ atom is replacing $\mathrm{C}$ atom of a graphene sheet, it creates an interaction with a few electronic levels close to the Fermi energy of metallic behaviour. In this case, the Ag atom acts as an electron donor that could increase metallicity of the nanotubes. It follows the same theory applied when Nickel nanoparticles decorated CNT [39].

3.4. Thermogravimetric Analysis. Figure 6 shows the TGA curves of pristine MWNT and MWNT-Ag hybrids with different volume of AgNP. The initial weight loss for all samples occurring in the range of $30-90^{\circ} \mathrm{C}$ is due to water removal at ambient temperature, followed by gradual weight loss within a temperature range of $90-480^{\circ} \mathrm{C}$ due to physical damage resulting from the carbon content. It can be seen from the TGA traces that the change in weight loss is rather drastic within a temperature range of $480-950^{\circ} \mathrm{C}$. As we can observe, the MWNT-Ag hybrids showed decomposition at a lower temperature compared to the pristine MWNT. In fact, the MWNT-Ag hybrids yield increasing residual mass with an increase of AgNP presence in the MWNT hybrids. Therefore, the thermal stability of MWNT in the air was decreased with increasing AgNP attached to the nanotube surface by catalysing the oxidation temperature of MWNT. This is because Ag is an effective oxidation catalyst that can split oxygen molecules into atoms and these atoms can be lightly adsorbed onto MWNT surface. In addition, the AgNP could create sites for the oxidation of oncoming chemical compounds [21, 40]. This is in agreement with work done by Xin and Li, who discussed that the direct deposition of AgNP onto the CNT surface accelerates the decomposition of CNT more effectively compared to microsized Ag [11].

The oxidation temperature is determined from the derivative thermogravimetric analysis (DTG) profiles, as shown in Figure 7. The crystalline structure of MWNT shows a narrow oxidation peak within a temperature range of 500$550^{\circ} \mathrm{C}$, whereas the oxidation of amorphous carbon in the MWNT occurs within a lower temperature range of 200$300^{\circ} \mathrm{C}$ [37]. The peak remaining between 800 and $900^{\circ} \mathrm{C}$ is due to the iron present in the pristine MWNT. The oxidation peaks of MWNT-Ag hybrids slightly shifted from $526^{\circ} \mathrm{C}$ to $544^{\circ} \mathrm{C}$ with increasing AgNP from 10 to 70 vol\%, which is followed by a significant drop in the decomposition peaks. It shows that the MWNT-Ag hybrids decompose at a much faster rate and the weight loss decreased considerably due to the presence of AgNP. It can be seen that the breadth of the derivative peaks for MWNT-Ag hybrids also increases when compared to the pristine MWNT due to the increased defects on graphitic network of the nanotube [41]. 


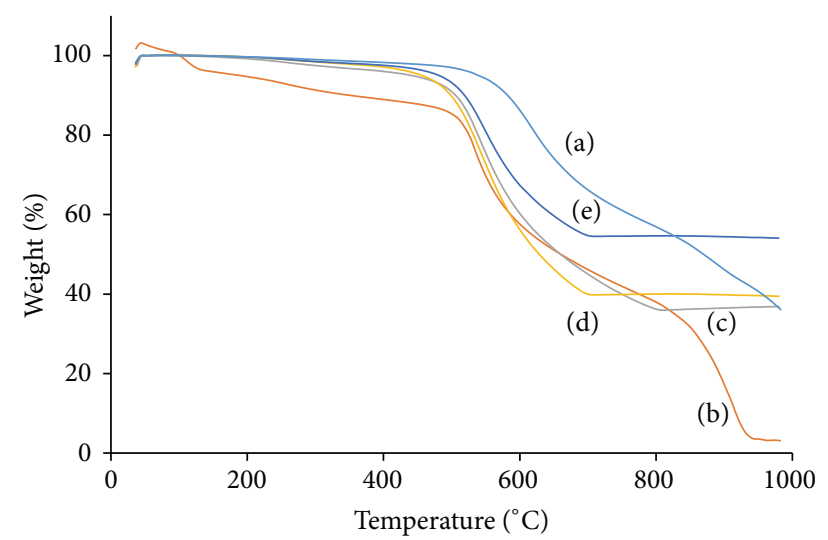

Figure 6: TGA curves of (a) pristine MWNT and MWNT-Ag hybrids with different vol\% of AgNP: (b) 10, (c) 30, (d) 50, and (e) 70 .

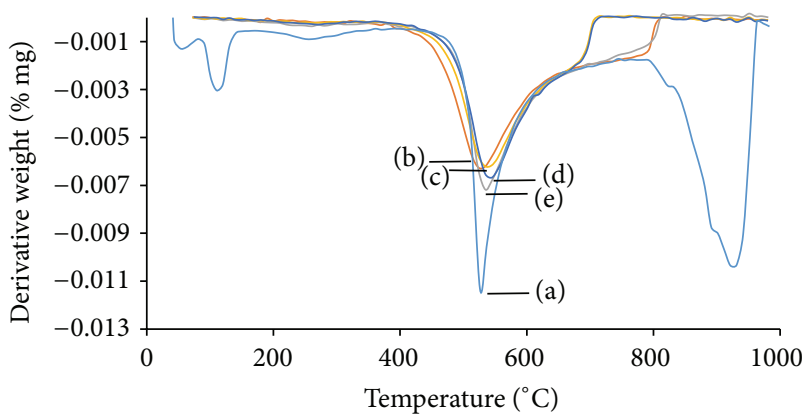

FIGURE 7: DTG curves of (a) pristine MWNT and MWNT-Ag hybrids with different vol\% of AgNP: (b) 10, (c) 30, (d) 50, and (e) 70 .

3.5. I-V Characteristics. Figure 8 shows the current-voltage $(I-V)$ curves of the pristine MWNT and MWNT-Ag hybrids as a function of gate voltage $\left(V_{\mathrm{g}}\right)$. Such typical nonlinear $I-V$ curves verify that the samples have a depletion mode that is similar to the behaviour of metal oxide semiconductor fieldeffect transistors (MOSFET) [42]. The $I-V$ curve for all samples indicates that the drain current increases gradually with an increase in the gate voltage $\left(V_{\mathrm{g}}\right)$. The number of electrons increases in the channel above the threshold voltage $\left(V_{\mathrm{th}}\right)$ and, thus, the drain current increases rapidly with a minor increase in the drain voltage until it becomes saturated at the output voltage. The current at the maximum gate voltage is the "on" current. The semiconducting characteristics of all samples are ascertained by the dependence of the source-drain voltage on the gate voltage. The samples show p-type characteristics with FET configuration where the drain is lower than the source voltage by taking the source to drain voltage $\left(V_{\mathrm{SD}}\right)$ that is fixed at $10 \mathrm{~V}$. It is suggested that doping the MWNT surface with AgNP could change its characteristics from p-type to n-type due to the occurrence of charge-transfer because the current flow only occurs through outermost of the nanotubes [43].

Thereby, the electrical transport of pristine MWNT is improved when charge carriers are doped in the MWNT-Ag hybrids. In this case, the $I-V$ curves for MWNT-Ag hybrids were shifted at lower $V_{\text {th }}$ with an increase in the volume

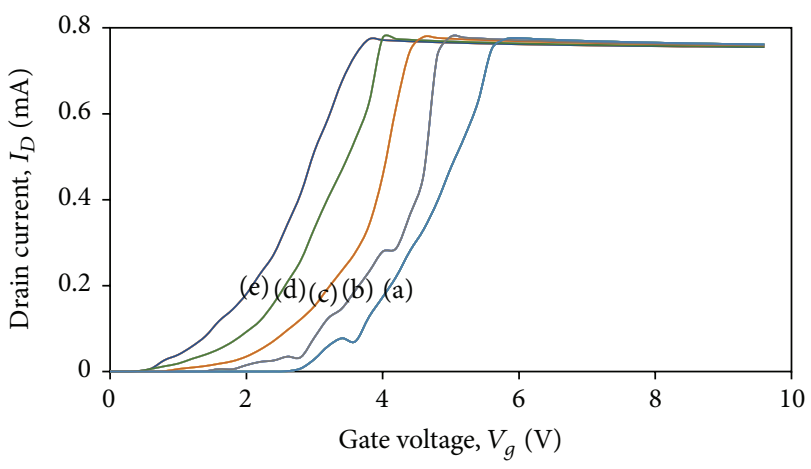

FIGURE 8: $I-V$ characteristics of (a) pristine MWNT and MWNT-Ag hybrids with different vol\% of AgNP: (b) 10, (c) 30, (d) 50, and (e) 70 .

fraction of AgNP. The $V_{\text {th }}$ value for the MWNT-Ag hybrids with the highest loading of AgNP (70 vol\%) is reduced by $65 \%$ relative to the pristine MWNT. It may claim that the doping of MWNT with increasing AgNP could change the tubetube contact resistance and improve conduction in the device. In such case, the $V_{\text {th }}$ value decreases with increasing AgNP indicating a lower gate voltage than the pristine MWNT, but the current saturation is observed at about $0.75 \mathrm{~mA}$ for all samples. It suggests that the resistance of MWNT remains at $13 \mathrm{k} \Omega$ and changing the doping concentration of the AgNP did not easily change the semiconductor characteristics. Increasing the gate voltage turns the valence band of nanotubes closer to the source Fermi level. Once the tunnelling barrier for hole injection becomes thinner, the resulting drain current exponentially increases and becomes saturated when the charge starts to accumulate in the MWNT channel [13]. In fact, intrinsic tube properties dominate the electrical transport properties of the nanotubes, but electrical transport of MWNT in FET configuration is influenced by the Schottky barrier at the metal-nanotube contact interface $[42,44]$.

\section{Conclusion}

In this study, the MWNT-Ag hybrids are synthesized by reducing aqueous silver salt in the presence of SDS as stabilizing agent to enhance the deposition of AgNP onto MWNT surface. The MWNT was functionalized through mild oxidation treatment based on sonicating the MWNT in $\mathrm{HNO}_{3}$ followed by $\mathrm{H}_{2} \mathrm{O}_{2}$, in order to care for structural and electrical reinforcement of the MWNT-Ag hybrids. The findings of this study indicate that MWNT-Ag hybrids have enhanced the structural, thermal, and electrical characteristics of pristine MWNT. The FESEM and TEM images display morphology structure of the MWNT-Ag hybrids with increasing AgNP. The FTIR spectra show that interactions between the Ag cations and carboxyl groups result in the attachment of AgNP onto the MWNT through van der Waals forces and electrostatic interactions. The deposition of AgNP onto the MWNT surface results in broadening of the D- and G-bands that suggest the occurrence of charge-transfer between AgNP and sidewalls of the MWNT, which is enhanced by hydrophobic 
interaction with SDS molecules due to a substantial change in the electronic density state of the nanotubes. The $\mathrm{G}^{\prime}$-band intensity also slightly increased due to enhanced metallicity of the nanotubes. Thermogravimetric analysis (TGA) shows that the MWNT-Ag hybrids decompose at a much faster rate and the weight loss decreased considerably due to the presence of AgNP. The electrical characteristics of MWNTAg hybrids obtained through this work can be enhanced via mild functionalization of the nanotubes by adding SDS as the surfactant. The nonlinearity of $I-V$ curves indicates that electrical transport of pristine MWNT is enhanced when AgNP is induced as charge carriers in the MWNT-Ag hybrids. The $V_{\text {th }}$ value for the MWNT doped with a maximum of 70 vol $\%$ of AgNP was substantially reduced by $65 \%$ relative to the pristine MWNT. Therefore, MWNT-Ag hybrids are promising materials to improve their electrical properties for FET applications with a low threshold voltage.

\section{Competing Interests}

The authors declare that they do not have any competing interests.

\section{Acknowledgments}

The authors wish to extend their greatest appreciation to the Ministry of Education Malaysia and University of Malaya for providing the financial support for this work under University Malaya Research Grant Scheme (Grant no. RP011C13AET) and Postgraduate Research Fund (Grant no. PG0842012B and PG165-2015B).

\section{References}

[1] S. Iijima, "Helical microtubules of graphitic carbon," Nature, vol. 354, no. 6348, pp. 56-58, 1991.

[2] P. C. Ma, B. Z. Tang, and J.-K. Kim, "Effect of CNT decoration with silver nanoparticles on electrical conductivity of CNTpolymer composites," Carbon, vol. 46, no. 11, pp. 1497-1505, 2008.

[3] M. M. J. Treacy, T. W. Ebbesen, and J. M. Gibson, "Exceptionally high Young's modulus observed for individual carbon nanotubes," Nature, vol. 381, no. 6584, pp. 678-680, 1996.

[4] P. Chen, X. Wu, X. Sun, J. Lin, W. Ji, and K. L. Tan, "Electronic structure and optical limiting behavior of carbon nanotubes," Physical Review Letters, vol. 82, no. 12, pp. 2548-2551, 1999.

[5] D. G. Larrude, M. E. H. Maia da Costa, and F. L. Freire Jr., "Synthesis and characterization of silver nanoparticle-multiwalled carbon nanotube composites," Journal of Nanomaterials, vol. 2014, Article ID 654068, 7 pages, 2014.

[6] A. Yu, Q. Wang, J. Yong et al., "Silver nanoparticle-carbon nanotube hybrid films: preparation and electrochemical sensing," Electrochimica Acta, vol. 74, pp. 111-116, 2012.

[7] D. J. Guo and H. L. Li, "Highly dispersed Ag nanoparticles on functional MWNT surfaces for methanol oxidation in alkaline solution," Carbon, vol. 43, no. 6, pp. 1259-1264, 2005.

[8] W. Yuan, G. Jiang, J. Che et al., "Deposition of silver nanoparticles on multiwalled carbon nanotubes grafted with hyperbranched poly(amidoamine) and their antimicrobial effects,"
Journal of Physical Chemistry C, vol. 112, no. 48, pp. 18754-18759, 2008.

[9] K. C. Chin, A. Gohel, W. Z. Chen et al., "Gold and silver coated carbon nanotubes: an improved broad-band optical limiter," Chemical Physics Letters, vol. 409, no. 1-3, pp. 85-88, 2005.

[10] D. K. Venkata Ramana, J. S. Yu, and K. Seshaiah, "Silver nanoparticles deposited multiwalled carbon nanotubes for removal of $\mathrm{Cu}(\mathrm{II})$ and $\mathrm{Cd}(\mathrm{II})$ from water: surface, kinetic, equilibrium, and thermal adsorption properties," Chemical Engineering Journal, vol. 223, pp. 806-815, 2013.

[11] F. Xin and L. Li, "Decoration of carbon nanotubes with silver nanoparticles for advanced CNT/polymer nanocomposites," Composites Part A: Applied Science and Manufacturing, vol. 42, no. 8, pp. 961-967, 2011.

[12] J.-M. Bonard, F. Maier, T. Stöckli et al., "Field emission properties of multiwalled carbon nanotubes," Ultramicroscopy, vol. 73, no. 1-4, pp. 7-15, 1998.

[13] J. Appenzeller, J. Knoch, R. Martel, V. Derycke, S. J. Wind, and P. Avouris, "Carbon nanotube electronics," IEEE Transactions on Nanotechnology, vol. 1, no. 4, pp. 184-189, 2002.

[14] G. G. Wildgoose, C. E. Banks, and R. G. Compton, "Metal nanoparticles and related materials supported on Carbon nanotubes: methods and applications," Small, vol. 2, no. 2, pp. 182193, 2006.

[15] B. Xue, P. Chen, Q. Hong, J. Lin, and Kuang Lee Tan, "Growth of $\mathrm{Pd}, \mathrm{Pt}, \mathrm{Ag}$ and Au nanoparticles on carbon nanotubes," Journal of Materials Chemistry, vol. 11, no. 9, pp. 2378-2381, 2001.

[16] S.-D. Oh, B.-K. So, S.-H. Choi et al., "Dispersing of Ag, Pd, and $\mathrm{Pt}-\mathrm{Ru}$ alloy nanoparticles on single-walled carbon nanotubes by $\gamma$-irradiation," Materials Letters, vol. 59, no. 10, pp. 1121-1124, 2005.

[17] J. Chen and G. Lu, "Carbon nanotube-nanoparticle hybrid structures," in Carbon Nanotubes, chapter 31, InTech, 2010.

[18] M. Ghalkhani, S. Shahrokhian, and F. Ghorbani-Bidkorbeh, "Voltammetric studies of sumatriptan on the surface of pyrolytic graphite electrode modified with multi-walled carbon nanotubes decorated with silver nanoparticles," Talanta, vol. 80, no. 1, pp. 31-38, 2009.

[19] Y. Liu, J. Tang, X. Chen, W. Chen, G. K. H. Pang, and J. H. Xin, "A wet-chemical route for the decoration of CNTs with silver nanoparticles," Carbon, vol. 44, no. 2, pp. 381-383, 2006.

[20] R. Sepahvand, M. Adeli, B. Astinchap, and R. Kabiri, "New nanocomposites containing metal nanoparticles, carbon nanotube and polymer," Journal of Nanoparticle Research, vol. 10, no. 8, pp. 1309-1318, 2008.

[21] F. Alimohammadi, M. P. Gashti, A. Shamei, and A. Kiumarsi, "Deposition of silver nanoparticles on carbon nanotube by chemical reduction method: evaluation of surface, thermal and optical properties," Superlattices and Microstructures, vol. 52, no. 1, pp. 50-62, 2012.

[22] S.-H. Lee, C.-C. Teng, C.-C. M. Ma, and I. Wang, "Highly transparent and conductive thin films fabricated with nanosilver/double-walled carbon nanotube composites," Journal of Colloid and Interface Science, vol. 364, no. 1, pp. 1-9, 2011.

[23] V. Georgakilas, D. Gournis, V. Tzitzios, L. Pasquato, D. M. Guldi, and M. Prato, "Decorating carbon nanotubes with metal or semiconductor nanoparticles," Journal of Materials Chemistry, vol. 17, no. 26, pp. 2679-2694, 2007.

[24] M. Ramin and F. Taleshi, "The effect of carbon nanotubes as a support on morphology and size of silver nanoparticles," International Nano Letters, vol. 3, no. 1, p. 32, 2013. 
[25] D. S. Ahmed, A. J. Haider, and M. R. Mohammad, "Comparesion of functionalization of multi-walled carbon nanotubes treated by oil olive and nitric acid and their characterization," Energy Procedia, vol. 36, pp. 1111-1118, 2013.

[26] F. Ahmadpoor, S. M. Zebarjad, and K. Janghorban, "Decoration of multi-walled carbon nanotubes with silver nanoparticles and investigation on its colloid stability," Materials Chemistry and Physics, vol. 139, no. 1, pp. 113-117, 2013.

[27] K. C. Song, S. M. Lee, T. S. Park, and B. S. Lee, "Preparation of colloidal silver nanoparticles by chemical reduction method," Korean Journal of Chemical Engineering, vol. 26, no. 1, pp. 153$155,2009$.

[28] F. Avilés, J. V. Cauich-Rodríguez, L. Moo-Tah, A. May-Pat, and R. Vargas-Coronado, "Evaluation of mild acid oxidation treatments for MWCNT functionalization," Carbon, vol. 47, no. 13, pp. 2970-2975, 2009.

[29] J.-C. Valmalette, Z. Tan, H. Abe, and S. Ohara, "Raman scattering of linear chains of strongly coupled Ag nanoparticles on SWCNTs," Scientific Reports, vol. 4, article 5238, 2014.

[30] L. Stobinski, B. Lesiak, L. Kövér et al., "Multiwall carbon nanotubes purification and oxidation by nitric acid studied by the FTIR and electron spectroscopy methods," Journal of Alloys and Compounds, vol. 501, no. 1, pp. 77-84, 2010.

[31] J. H. Lehman, M. Terrones, E. Mansfield, K. E. Hurst, and V. Meunier, "Evaluating the characteristics of multiwall carbon nanotubes," Carbon, vol. 49, no. 8, pp. 2581-2602, 2011.

[32] N. Izadi, A. M. Rashidi, S. Golzardi, Z. Talaei, A. R. Mahjoub, and M. H. Aghili, "Hydrogen sulfide sensing properties of multi walled carbon nanotubes," Ceramics International, vol. 38, no. 1, pp. 65-75, 2012.

[33] F. A. Abuilaiwi, T. Laoui, M. Al-Harthi, and M. A. Atieh, "Modification and functionalization of multiwalled carbon nanotube (MWCNT) via fischer esterification," Arabian Journal for Science and Engineering, vol. 35, no. 1, pp. 37-48, 2010.

[34] G. Bounos, K. S. Andrikopoulos, T. K. Karachalios, and G. A. Voyiatzis, "Evaluation of multi-walled carbon nanotube concentrations in polymer nanocomposites by Raman spectroscopy," Carbon, vol. 76, pp. 301-309, 2014.

[35] H. Yu, J. Peng, M. Zhai, J. Li, and G. Wei, "Silver nanowires formed within multi-walled carbon nanotubes by radiationinduced reduction of silver ions," Physica E, vol. 40, no. 8, pp. 2694-2697, 2008.

[36] A. Eckmann, A. Felten, A. Mishchenko et al., "Probing the nature of defects in graphene by Raman spectroscopy," Nano Letters, vol. 12, no. 8, pp. 3925-3930, 2012.

[37] L. Vaisman, H. D. Wagner, and G. Marom, "The role of surfactants in dispersion of carbon nanotubes," Advances in Colloid and Interface Science, vol. 128-130, pp. 37-46, 2006.

[38] K. K. Kim, J. S. Park, S. J. Kim et al., "Dependence of Raman spectra $\mathrm{G}^{\prime}$ band intensity on metallicity of single-wall carbon nanotubes," Physical Review B, vol. 76, no. 20, Article ID 205426, 2007.

[39] C. Bittencourt, A. Felten, J. Ghijsen et al., "Decorating carbon nanotubes with nickel nanoparticles," Chemical Physics Letters, vol. 436, no. 4-6, pp. 368-372, 2007.

[40] I. W. Chiang, B. E. Brinson, R. E. Smalley, J. L. Margrave, and R. H. Hauge, "Purification and characterization of single-wall carbon nanotubes," The Journal of Physical Chemistry B, vol. 105, no. 6, pp. 1157-1161, 2001.

[41] M. A. M. Motchelaho, H. Xiong, M. Moyo, L. L. Jewell, and N. J. Coville, "Effect of acid treatment on the surface of multiwalled carbon nanotubes prepared from Fe-Co supported on $\mathrm{CaCO}_{3}$ : correlation with Fischer-Tropsch catalyst activity," Journal of Molecular Catalysis A: Chemical, vol. 335, no. 1-2, pp. 189-198, 2011.

[42] I. Ferain, C. A. Colinge, and J.-P. Colinge, "Multigate transistors as the future of classical metal-oxide-semiconductor field-effect transistors," Nature, vol. 479, no. 7373, pp. 310-316, 2011.

[43] P. R. Bandaru, "Electrical properties and applications of carbon nanotube structures," Journal of Nanoscience and Nanotechnology, vol. 7, no. 4-5, pp. 1239-1267, 2007.

[44] J. Svensson and E. E. B. Campbell, "Schottky barriers in carbon nanotube-metal contacts," Journal of Applied Physics, vol. 110, no. 11, Article ID 111101, 2011. 

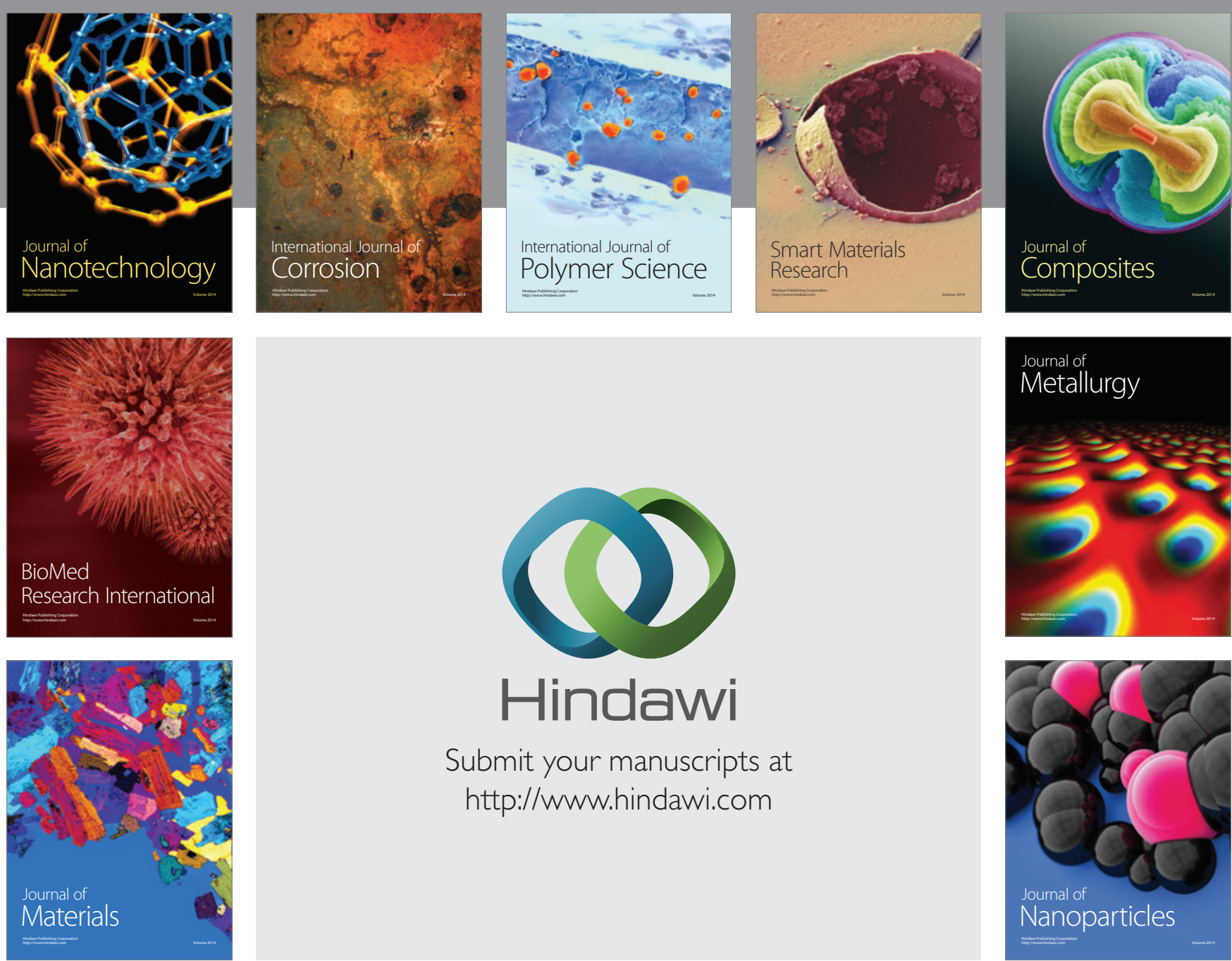

\section{Hindawi}

Submit your manuscripts at

http://www.hindawi.com

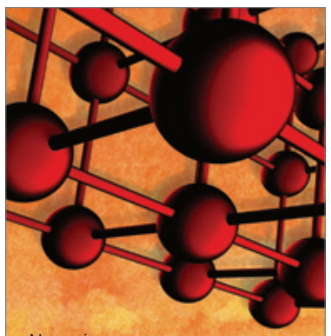

Materials Science and Engineering
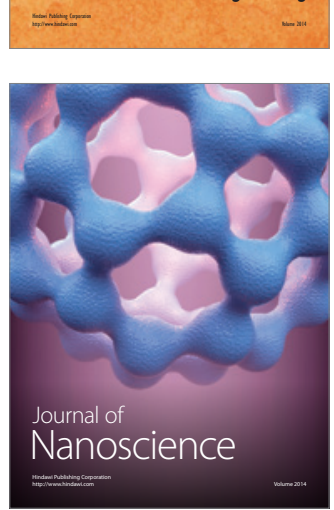
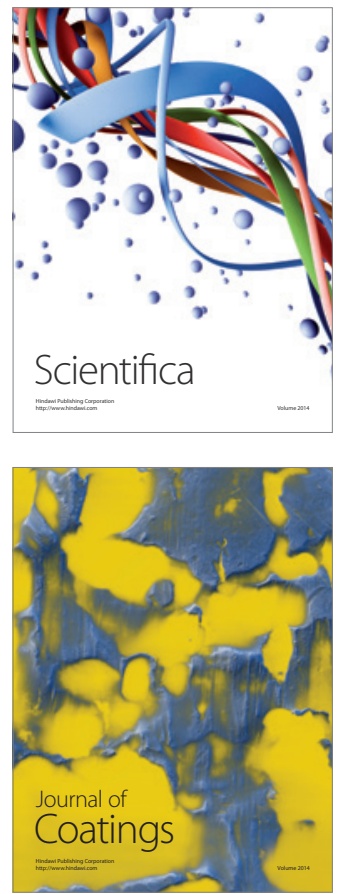
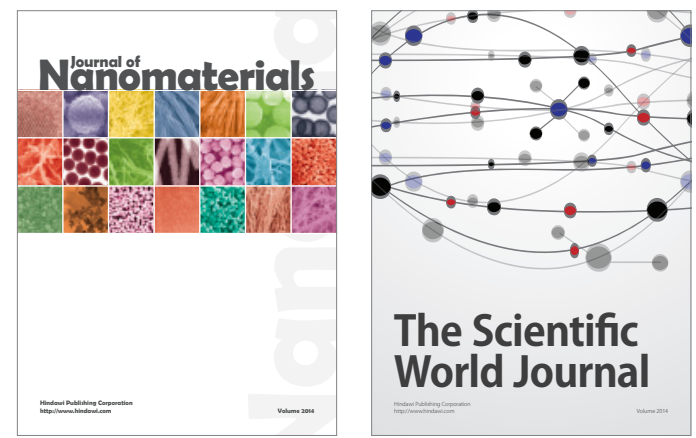

The Scientific World Journal
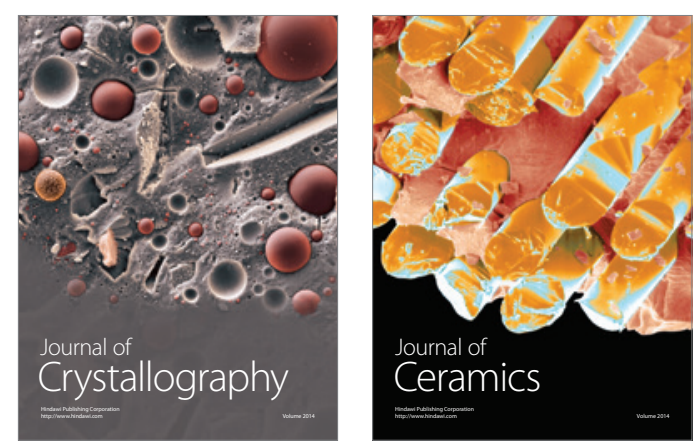
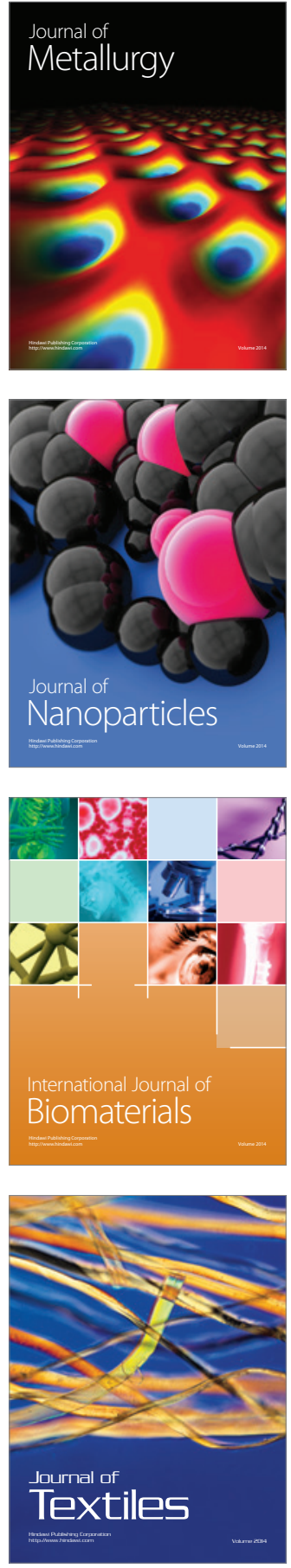